\title{
ДОЛГИЙ ПУТЬ К «ЦЕНТРАЛИЗАЦИИ»: РАННЕМОДЕРНОЕ РУССКОЕ ГОСУДАРСТВО И ЕГО ОСОБЕННОСТИ
}

\author{
LONG WAY TO "CENTRALIZATION": \\ EARLY MODERN RUSSIAN STATE AND ITS FEATURES
}

\author{
В.В. Пенской, Л.А. Пожарова, В.Ю. Туранин \\ V.V. Penskoy, L.A. Pozharova, V.Yu. Turanin \\ Белгородский государственный национальный исследовательский университет, \\ Россия, 308015, г. Белгород, ул. Победы, 85 \\ Belgorod National Research University, \\ 85 Pobeda St, Belgorod, 308015, Russia \\ E-mail: penskoy@bsu.edu.ru,pozharova@bsu.edu.ru, turanin@bsu.edu.ru
}

\begin{abstract}
Аннотация
Проблемы, связанные с особенностями протекания процесса «централизации» и формирования властных институтов и структур в России раннего Нового времени (2-я половина XV - начало XVII вв.), являются предметом оживленных дискуссий между историками. Во 2-й половине минувшего столетия окончательно сформировалась историографическая традиция, исходившая из того, что раннемодерное Российское государство являлось «централизованным», унифицированным в административном и правовом отношениях, с сильной властью монарха. Однако в последнее время эта концепция подвергается критике и постепенно размывается. Авторы, опираясь на последние наработки в российской и зарубежной историографии, предлагают взглянуть на сущность раннемодерного Российского государства «изнутри». По мнению авторов, Российское государство этого времени отличалось от своих предшественников большей внутренней консолидацией, однако все же не может быть названо действительно «централизованным». Развиваясь эволюционным путем, опираясь на «старину», оно сохраняло множество пережитков прошлого в политической, правовой, административной и иных сферах. Эти пережитки налагали определенные серьезные ограничения на верховную власть и препятствовали быстрому совершенствованию и наращиванию властной инфраструктуры. Слабое институционально, раннемодерное Российское государство было вынуждено опираться на поддержку общества, «земли», согласовывать свои действия и желания с его интересами. В результате к исходу раннего Нового времени процессы «централизации» в России еще были далеки от завершения.
\end{abstract}

\footnotetext{
Abstract

The features of the processes of "centralization" and the formation of power institutions and structures in Russia of the early New Age (2nd half of the 15th - beginning of the 17th centuries) have long been the subject of lively discussions between historians. In the 2 nd half of the last century, a stable historiographic tradition was finally formed. It proceeds from the fact that the early-modern Russian state was "centralized", unified in administrative and legal relations, with the strong power of the monarch. Recently, however, this concept has been criticized and gradually eroded. In the article, the authors, relying on the latest developments in Russian and foreign historiography, propose to look at the essence of the early-modern Russian state from the inside. According to the authors, the Russian state of this time was distinguished from its predecessors by greater internal consolidation. However, it cannot be called truly "centralized." It developed in an evolutionary way, based on tradition and custom. As a result, the Russian state retained many remnants of the past in the political, legal, administrative and other fields. These remnants imposed certain serious restrictions on the supreme power and prevented the rapid improvement and expansion of the power infrastructure. Weak institutionally, early modern Russian state
} 
was forced to rely on the support of society and coordinate its actions and desires with its interests. According to the authors, by the end of the early New Age, the processes of "centralization" in Russia were still far from complete.

Ключевые слова: раннее Новое время, политический режим, «композитное» государство, централизация, самодержавие, бюрократия, Русское государство, Иван Грозный.

Keywords: Early Modern, political regime, "composite" state, centralization, autocracy, bureaucracy, Russian state, Ivan the Terrible.

\section{Введение}

С середины минувшего столетия в отечественной исторической науке устоялось (и продолжает господствовать) мнение о Российском государстве раннего Нового времени как о «централизованном». Этому вопросу посвящена обширнейшая историография, и даже простое перечисление работ, в которых так или иначе она затрагивается, занял бы не один десяток страниц. Ограниченный объем этой статьи не позволяет нам остановиться подробнее на анализе данной проблемы, дадим лишь отсылку к классическим исследованиям на эту тему - например, к «Образованию Русского централизованного государства в XIV - XV веках» Л.В. Черепнина [1960], или «России на рубеже XV-XVI столетий» А.А. Зимина [1982], или сборникам статей [Россия..., 1982]. Для того, чтобы кратко сформулировать сущность этого «централизованного» государства в рамках традиционной концепции, обратимся к определению российского историка А.И. Филюшкина, пожалуй, лучшему из всех. По его мнению, под «централизованным государством» «понималось прежде всего государство, унифицированное в административном и институциональном плане (выделено нами - aвm.)» [Филюшкин, 2009, с. 5].

Исходя из этого определения, можно с уверенностью сказать, что «классическое» «централизованное» государство раннего Нового времени является единым, внутренне консолидированным политическим образованием, унифицированным в административном, институциональном, правовом (как минимум, поскольку можно без особого труда вывести и иные уровни централизации) отношении. Тем самым оно выгодно отличается от рыхлых средневековых политий с их характерным признаком - «рассеянным» суверенитетом. Отражая господствующее мнение, школьные и университетские учебники приписывают честь создания этого государства могущественному Ивану III, а завершение этого процесса относят ко временам его внука Ивана IV, вошедшего в историю под прозвищем Грозный. Последний, если верить немецкому авантюристу Генриху Штадену, «добился того, так как по всей Русской земле, то есть под его державой, единая вера, единый вес, единая мера, что он один и правит (ein glaub, ein gewichte eine masse ist das her auch alleine Regirett), что все, что он велит, должно свершиться, а от всего, что он запретит, следует отказаться» [Штаден, 2008, с. 203, с. 205].

Стоит, однако, отметить, что далеко не все специалисты по истории Русского государства раннего Нового времени полностью разделяют эту точку зрения - есть сомневающиеся в том, что раннемодерное Московское царство было действительно «централизованным» в той степени, в какой его принято описывать согласно устоявшейся традиции. К числу таких «инакомыслящих» можно отнести российского историка С.О. Шмидта. Еще в 1973 г., характеризуя особенности развития Российского государства в московский период его истории, он указывал на то, что «в России XVI-XVII вв. имела место не столько централизация, сколько бюрократизация управления, унификация правовых норм, финансовой системы, военнослужебных отношений» [Шмидт, 1973, с. 310 ].

Трудно, на первый взгляд, оспорить мнение известного специалиста по раннемодерной русской истории. В самом деле, с принятием двух судебников 1497 и 1550 гг. судебные процедуры на всей территории Русского государства действительно постепенно унифицировались; финансовая реформа «правительства» Елены Глинской, «регентши» 
при малолетнем Иване IV, привела в соответствие новгородскую и московскую денежные системы; в рамках программы «реформ» конца 40-х - 50-х гг. XVI в. (мы не случайно взяли в кавычки термин «реформы», поскольку есть и иные мнения на этот счет [Krom, 2009]), осуществленных пресловутой «Избранной радой», была сделана попытка «стандартизировать», привести к единому образцу порядок несения государевой службы детьми боярскими - вотчинниками и помещиками; к более или менее единому «стандарту» были приведены усилиями митрополита Макария и его единомышленников (при активном участи и поддержке верховной власти) порядки внутри русской церкви. И, естественно, никак нельзя пройти мимо формирования приказной системы, пришедшейся на время правления Ивана Грозного.

Однако стоит ли так прямолинейно, как это делает С.О. Шмидт, противопоставлять или же «выпячивать» на первый план «бюрократизацию» взамен «централизации»? Или все же стоит вести речь о внутренней «институционализации» Русского государства, составными частями которой были и «централизация», и «бюрократизация», и «унификация»? Попробуем разобраться в этом.

\section{Основная часть}

На протяжении долгого времени, анализируя процессы политогенеза, историки обращали внимание в первую очередь на внешние проявления этого процесса, на его форму, но не на внутреннее содержание. Однако если заглянуть в «закулисье», сосредоточиться на изучении содержания политической кухни, рассматривать государство и его эволюцию как институциональное образование, то ситуация меняется. Как отмечал российский историк К.В. Петров, анализируя особенности «содержания» Российского государства в раннее Новое время, «государство XVI-XVII вв. слабый социальный институт по сравнению с современным государством». Как результат, продолжал историк свою мысль, «слабой была не власть Ивана III или Василия III над своими боярами, относительно слабым было государство в возможности осуществлять меры принуждения в отношении населения», и по этой причине «государство, будучи не в состоянии своими силами обеспечить соблюдение правопорядка (и не только его одного - Aвт.) на территории страны, для решения указанной задачи привлекало само общество...» [Петров, 2008, с. 375, с. 376]. На это обстоятельство, кстати, обращал внимание еще в 1991 г. Н.Н. Покровский. Во введении к исследованию Ю.Г. Алексеева об Иване III он писал, что «власть эта (великого князя Aвm.) была не так уж и сильна, что местные особенности и различия очень долго давали себя знать в едином государстве... Система власти базировалась не на единственном понятии "государство", а на двух понятиях - "государство" и "общество", на продуманной системе не только прямых, но и обратных связей между ними... Центральная государственная власть того времени не была в состоянии доходить до каждой отдельной личности; исполняя свои функции, она должна была опираться на эти первичные социальные общности (крестьянские и городские "миры", служилые корпорации-города и пр. - Aвm.). Но это автоматически означало серьезные права таких организмов, их немалую роль в политической системе всей страны (выделено нами - Авт.) ...» [Алексеев, 1991, с. 5-6].

Любопытно сравнить эти слова с наблюдениями, которые сделала, к примеру, К. Барки применительно к Османской империи раннего Нового времени. Она указывала на то, что имперские власти, стремясь сохранить управляемость своими владениями, вынуждены были «разделять контроль со множеством промежуточных структур и с местными элитами, религиозными и местными структурами и многочисленными иными привилегированными институциями» [Barkey, 2008, p. 10]. По сути, здесь сказано тоже, что и в предыдущей цитате, только несколько иными словами. И ведь можно привести и другие примеры - не только Российское государство или Османская империя в раннее Новое время были институционально слабыми государствами (при том, что, подчеркнем, отдельно взятые монархи могли обладать немалой властью). 
Развивая этот тезис, отметим, что, на наш взгляд, эти наблюдения могут быть вполне соотнесены и с другими современными России и Турции государствами Европы хотя бы с той же Францией, страной, как принято считать, рано вступившей на путь политической централизации и ставшей во 2-й половине XVII в. страной классического же абсолютизма. Между тем, как отмечала С. Кэрролл, в раннее Новое время (а по существу до самого конца пресловутого Ancien Régime) «Франция была "составным" государством, государством, которое так и не сумело прочно соединить в одно целое области с характерными для них отличительными чертами и идентичностями» [Carroll, 2006, p. 331], страной, в которой, как показал Н. Хеншелл, «французские короли не управляли национальным государством, и при этом "нация" еще не являлась значимым феноменом. "Нация" в политическом, расовом или лингвистическом смысле была слишком туманным понятием, чтобы стать основой лояльности - ключевого элемента в это время. Люди были лояльны к своей семье, своему сеньору, своему городу, своей области, своему классу, своей религии или своему королю. Намного реже они были лояльны к своей стране... Без связующего начала реально существующего национального чувства административное и юридическое единство отсутствовало...» [Henshall, 1992, p. 8].

В подобного рода государственных образованиях раннего Нового времени, которые Дж. Эллиотт метко назвал «составными монархиями» (composite monarchies) [Elliott, 1992], процессы пресловутой «централизации» были весьма и весьма далеки от завершения, ибо верховная власть, не обладая необходимыми ресурсами (административными, финансовыми и людскими) и влиянием, была вынуждена идти на компромиссы, договариваться с местными элитами, соглашаться на сохранение традиционных «свобод» и привилегий, то есть «старины», в обмен на лояльность новых подданных. Естественно, что это вело к тому, что в рамках «старины» сохранялась масса пережитков прежнего политического, административного, правового устройства, явно несовместимых с самой сущностью понятия «централизация».

Вместе с тем нетрудно заметить, что постепенно, шаг за шагом, эволюционным путем верховная власть расширяла сферу своего влияния, наращивала то, что Дж. Брюэр именовал «жилами власти» («sinews of power») [Brewer, 1989], а мы предлагаем использовать несколько иной термин - «мускулатура власти» или, что еще лучше, на наш взгляд, отражает сущность этого явления, «инфраструктура власти».

Что представляла собой эта «инфраструктура» - лучшую ее характеристику, краткую, лаконичную, но вместе с тем достаточно емкую, дала Н. Коллманн. Историк отмечала, что она представляла собой «новые налоги и бюрократические структуры для управления территориями, сбора податей и мобилизации людских и материальных ресурсов», которые подкреплялись и узаконивались «новыми кодификациями права и новыми централизованными юридическими системами», а также соответствующей конфессиональной политикой и созданием тесно связанной с последней и опиравшейся на нее новой политической идеологией [Kollmann, 2012, c. 1].

При этом, осознавая слабость, верховная власть в своих «ползучих» преобразованиях должна была действовать осторожно, не торопясь, сообразуя те или иные шаги с мнением и интересами «политического народа», тех самых «местных элит, религиозных и провинциальных властных структур и многочисленных иных привилегированных институций», без поддержки и лояльности со стороны которых действия «правительства» были обречены на неудачу. Для России это было тем более важно, что, по замечанию Н. Коллманн, «в раннемодерной России у государства было слишком мало чиновников для обширной и малонаселенной территории с тем, чтобы они могли более или менее эффективно управляли ею, не прибегая к помощи и поддержке местных жителей» [Kollmann, 2012, с. 425].

Итак, общий «тренд» в развитии европейских государств раннего Нового времени заключался в развитии бюрократических структур, способных мобилизовать ресурсы, необходимые для реализации активной экспансионистской политики (а XVI век, составивший важнейшую часть интересующего нас периода, по меткому замечанию Р. МакКенни, 
был веком экспансии [MacKenney, 2002]); совершенствовании фискальной системы; активной кодификационной деятельности верховной власти, закреплявшей и узаконивавшей тем самым результаты своей деятельности; религиозной «унификации» и создании новой идеологии.

Можно ли выделить эти направления в деятельности русского «правительства» в эпоху правления последних Рюриковичей? Вне всякого сомнения. За немногим более чем столетие - со времени вокняжения Ивана III в 1462 г. до начала 80-х гг. следующего столетия, к моменту завершения правления внука Ивана III Ивана Грозного - Российское государство, сохраняя внешнюю форму, внутри подверглось серьезным переменам. Наиболее значимой из них, на наш взгляд, была бюрократическая «реформа» (если так ее можно назвать - мы исходим из того, что московское общество того времени, будучи «холодным» и чрезвычайно консервативным, противилось резким переменам).

Если кратко, то суть этой важнейшей реформы заключалась прежде всего в формировании приказной системы со всеми присущими ей особенностями, внешними и внутренними. Историография вопроса насчитывает не одну сотню работ, больших и малых, и не один десяток лет всестороннего изучения [Лисейцев, Рогожин, Эскин, 2015]. Для нас же важнее другое - найти ответ на вопрос, была ли приказная «реформа» одномоментным актом, «триумфом воли», или же приказы как органы центральной администрации медленно «прорастали» через толщу «старины»?

Ответ на этот вопрос может быть только один - приказы не возникли из ниоткуда, враз и уже в готовом виде. Нет, они стали результатом долгой эволюции государевой дворцовой администрации, которая складывалась при первых московских князьях в 1-й половине XIV в. (впрочем, этого и следовало ожидать, так как, на наш взгляд, развитие основных государственных институтов и в России, и в других государствах Европы в раннее Новое время шло преимущественно эволюционным путем). В свою завершающую стадию этот процесс вступил при Иване Грозном, когда приказная система приняла в основном завершенный вид, и более она уже не изменялась радикально - вплоть до эпохи Петра I. К концу его правления насчитывалось примерно полтора десятка приказов (без учета приказов митрополичих и дворовых), установился порядок приказного делопроизводства (с одновременным существенным ростом «бумажной» производительности приказов [Кром, 2010]), сфера их компетенции и юрисдикции и пр.

Однако, пожалуй, даже не это представляется важным во всей истории с приказами. М.М. Кром отмечал в последней своей работе, что характерной чертой формирования новой «вертикали» власти стала ее деперсонализация, нарастающая концентрация реальной власти в руках приказных людей [Кром, 2010]. «Делегирование властных полномочий государя его советникам и постепенная бюрократизация управления заметны в Московском государстве уже со второй половины XV столетия», - отмечает он, подчеркивая, что эта «родовая» черта характерна для любого модерного государства - и для Франции, и для Османской империи, и для России [Кром, 2018, с. 18]. В самом деле - бояре приходили и уходили, а вот дьяки и в особенности подьячие в приказах оставались, и от них в первую очередь зависела бесперебойная и эффективная работа приказов. Косвенным симптомом роста влияния дьяков и их политической значимости стало введение их в состав Боярской думы (через учреждение чина думного дьяка). Любопытно заметить в этой связи, что это усиление позиций приказных чинов в правящей элите Российского государства в ущерб интересам старой аристократии было подмечено князем А.М. Курбским и его конфидентом - беглым стрелецким головой, монахом-расстригой Т. Тетериным. Они в резкой форме критиковали Ивана Грозного за то предпочтение, которое он оказывает приказным перед старыми, «дородными» фамилиями.

И нельзя пройти мимо еще одного аспекта приказной службы, на который обратил внимание К.В. Петров. Он отмечал, что «принципы функционирования системы центрального (приказного) управления России XVI-XVII вв. в большей степени сближают ее с современным пониманием принципов государственной службы, нежели развитие госу- 
дарственного механизма европейских стран указанного времени» [Петров, 2011, 177]. В этом смысле Россия во многом опережала ту же Францию с ее архаичной практикой продажи должностей.

Активная внешняя политика была невозможна не только без создания соответствующей бюрократической машины и административного аппарата, способного мобилизовать ресурсы страны для успешной внешней экспансии. В этой связи нельзя не отметить, что, несмотря на свою малочисленность, профессионализм и эффективность приказного аппарата оказался достаточным для того, чтобы сделать возможной существенное расширение Российского государства и превращение его во 2-й половине XVI в. в подлинную империю. Финансы играли в решении этой проблемы далеко не последнюю роль. Чтобы не вдаваться глубоко в подробности финансовой политики последних Рюриковичей [Каштанов, 1988], отметим лишь два едва ли не самых важных, на наш взгляд, ее аспекта. Первый - это становление практики регулярных земельных описаний и составления фиксирующих их результаты писцовых книг. Надежно фиксируемое в источниках начало этой практики относится к концу XV в. (хотя можно предположить, что писцовые книги и (или) их аналоги появились существенно раньше), а спустя сто лет их составление стало обыденным делом.

Другой аспект финансовой политики московского «правительства» в эти десятилетия - унификация денежной системы в правление матери Ивана IV Елены Глинской и начавшийся процесс коммутации натуральных повинностей в денежные (который набирает обороты со времен казанских походов Ивана Грозного [Каштанов, 1988]). Впрочем, в силу отмеченного выше эволюционного характера развития государственных институтов, полной унификации и «стандартизации» выплат и повинностей в пользу казны добиться в русский «долгий XVI век» не удалось - этому препятствовало сохранение значительного числа жалованных верховной властью иммунитетных грамот [Каштанов, 1988]. И хотя верховная власть и пыталась неоднократно разрешить эту проблему, все же до конца справиться с нею так и не удалось.

Укреплению власти государя и расширению сферы его компетенции способствовала, естественно, и активная кодификационная политика. Правда, и здесь стоит отметить постепенность, эволюционность перемен. Знаменитый Судебник Ивана III, обнародованный в 1497 г., судя по всему, имел малое хождение и если и потеснил местный правовой обычай, то лишь частично [Петров, 2005]. Однако он заложил традицию, которая получит дальнейшее развитие и в немалой степени будет способствовать развитию процессов «централизации» в Российском государстве раннего Нового времени. Речь идет об унификации судебных процедур на всей территории Российского государства [Клосс Б.М., Назаров В.Д., 2000]. Как отмечала Н. Коллманн, «Судебник 1497 г. был прежде всего руководством для судей, определяя плату за услуги и описывая судебные процедуры», но при этом он «устанавливал высшую меру наказания для наиболее опасных преступлений (кража церковного имущества, измена, поджог, похищения и повторные преступления) и телесные наказания для менее опасных преступлений, равно как и штрафов-компенсаций за нанесение телесных повреждений» [Kollmann, 2012].

Царский Судебник, одобренный в 1550 г., продолжил эту линию, сосредоточившись на дальнейшем регулировании судебных процедур. Однако вместе с тем он расширил и сферу компетенции царского суда. В частности, в этом правовом кодексе более основательно и подробно был расписан порядок наказания превысивших свои полномочия должностных лиц (очевидно, что это нововведение было обусловлено последствиями бурных событий в Москве летом 1547 г. [Пенской, 2019]). И если оба этих судебника касались вопросов светского права, то постановления так называемого Стоглавого собора («Стоглав»), принятого тогда же, - проблем, связанных с унификацией норм канонического права на всей территории Российского государства. Отметим в этой связи, что Стоглавый собор сыграл чрезвычайно важную роль в стандартизации норм и правил, определявших внутреннюю жизнь Русской церкви в «долгий XVI век», и в этом смысле вполне 
укладывался в генеральную линию правительственной политики при последних Рюриковичах, нацеленной на достижение той самой пресловутой «централизации» через равно «собирание земель» (завершенное в общем и целом в начале XVI в.) и «собирание власти» (а вот этот процесс затянулся и даже во 2-й половине XVI в. был далек от завершения).

Кстати о «централизации» и «собирании власти». Нам представляется, что второй термин более емко и верно отражает сущность тех политических процессов и той политики, которую проводило «правительство» Ивана III, его сына и внука. В свое время великокняжеская власть явочным порядком (в рамках «семейного права», «corpus fratrum» Рюриковичей) оказалась рассеяна между множеством удельных князей, и великий князь был господином лишь в своем «домене». Теперь же московские государи, апеллируя к «старине», медленно, постепенно, шаг за шагом «собирали» власть в своих руках. «Единодержавие и самодержавие московских государей явилось итогом собирания раздробленной власти над территорией Великороссии и ее населением», - отмечал А.Е. Пресняков [Пресняков, 1918, с. 409]. И это собирание власти осуществлялось в первую очередь в тех самых формах, о которых шла речь выше, - создание административно-бюрократического аппарата, унификация судебных процедур и расширение сферы великокняжеской юрисдикции, совершенствование фискальной системы и пр. Но вместе с тем трудно не заметить, что, говоря обо всем этом, мы так или иначе говорим и о «централизации». Можно ли сказать в таком случае, что «централизация» - составная часть процесса «собирания власти»? В известном смысле, пожалуй, что можно, - с той лишь поправкой, что «централизация» включает в себя также и процесс «собирания земель» под властью московских государей. В некотором роде оба этих термина, «централизация» и «собирание власти», таким образом дополняют и перекрывают, но никак не заменяют друг друга, являясь частью одного и того же процесса формирования раннемодерного Российского государства. «Бюрократизация» же, отмеченная С.О. Шмидтом, на наш взгляд, является не более чем частью процесса «собирания власти», частью важной, однако не единственной.

Подведем общий итог всему вышесказанному. Несомненно, что Российское государство, возникшее в конце XV в. в результате последовательной объединительной политики московских великих князей, со времен Ивана Калиты (1325-1341 гг.) собиравших и земли, и власть в свои руки, отличалось от рыхлых, неконсолидированных, обладавших «рассеянным» среди множества удельных князей суверенитетом средневековых русских княжеств, - того же Великого Владимирского княжества, к примеру. Можно ли назвать это образовавшееся в исторически очень короткий срок государство «централизованным»? В определенном смысле - да. Однако не стоит одновременно преувеличивать степень его внутренней консолидации и «централизованности». Мы исходим из того, что сама по себе «централизация» - процесс многоплановый, многоуровневый, и на каждом его уровне он проходил с разной скоростью. В военной и политической сферах «централизация» была достигнута раньше, чем, скажем, в правовой области, и связано это было, несомненно, с теми процессами «накачивания» властной инфраструктуры, о которых говорилось прежде.

Вместе с тем, несмотря на определенные успехи в «собирании власти» последними Рюриковичами, считать их действительно подлинными автократорами-самодержцами, было бы, на наш взгляд, несколько преждевременно. Да, Иван III, Василий III и Иван IV были сильными монархами, яркими личностями, волевыми, авторитетными, харизматичными, обладавшими значительной властью (что так поражало иностранных наблюдателей - того же имперского дипломата С. Герберштейна). Но обладало ли государство само по себе силой, необходимой для того, чтобы навязать обществу, «земле» свою волю? Пожалуй, что еще нет. И стоит, на наш взгляд, согласиться с мнением К.В. Петрова, подчеркивавшего институциональную слабость раннемодерного Российского государства [Петров, 2008].

Эта слабость, в свою очередь, была следствием незавершенности процессов «собирания власти» и «централизации». Эта же незавершенность обуславливалась эволюционным путем развития русской государственности - «новизна» в нем медленно «прораста- 
ла» сквозь «старину», обретая тем самым необходимую для ее восприятия обществом легитимность (а вместе с тем еще и бедностью русского государства и общества). Тем не менее, подвижки, на первый взгляд незаметные, по прошествии нескольких десятков лет были - и значительные. Уже в малолетство Ивана IV, в эпоху «боярского» правления, степень деперсонализации власти была достаточно велика для того, чтобы растущий бюрократический аппарат сумел взять на себя немалую долю повседневной административной рутины и не допустить остановки работы государственной машины в условиях раздрая и хаоса в верхних эшелонах власти. Запас прочности центральных властных структур оказался достаточно велик и для того, чтобы позволить Ивану Грозному осуществить рискованный эксперимент с опричниной и не опрокинуть страну в очередную смуту, подобную той, что имела место в конце 30-х - первой половине 40-х гг. XVI в., в эпоху пресловутого «боярского правления». Подчеркнем - все это стало возможным во многом благодаря той самой «бюрократизации» (впрочем, она не была не только единственным, но даже и доминирующим фактором в этих процессах).

\section{Заключение}

Однако, завершая статью, еще раз подчеркнем - не стоит преувеличивать успехи верховной власти в деле «собирания власти» и «централизации» в «долгий XVI век». Начало XVII в, эпоха великой Смуты, едва не положившей конец Российскому государству как политическому субъекту, показала, что само по себе государство оказалось неспособным справиться с системным политическим и структурным кризисом. И здесь на помощь ему пришло земское самоуправление, окончательно конституированное при Иване Грозном и превратившееся пусть и в младшего, ведомого, но все же партнера верховной власти в деле управления государством. Это самоуправление, олицетворявшее собой «старину» (и опиравшееся на традицию), лишь в эпоху Петра Великого превратилось в подчиненного, зависимого, лишенного собственной воли и политической субъектности участника властных отношений. Свою роль, и немалую, в этом сыграла бюрократизация управления Московским государством - те тенденции, которые наметились при последних Рюриковичах, при первых Романовых набрали обороты и в конечном итоге позволили Петру I сделать решительный шаг на пути преобразования монархии земскосамодержавной в монархию бюрократически-самодержавную. Но это, подчеркнем, уже XVIII век, иная эпоха.

\section{Список литературы}

1. Алексеев Ю.Г. 1991. Государь всея Руси. Новосибирск, Наука: 239 с.

2. Зимин А.А. 1982. Россия на рубеже XV-XVI столетий (очерки социально-политической истории). М., Мысль: 333 с.

3. Каштанов С.М. 1988. Финансы средневековой Руси. М., Наука: 248 с.

4. Клосс Б.М., Назаров В.Д. 2000. Судебник 1497 г.: рукопись и текст. В кн.: Судебник 1497 г. в контексте истории российского и зарубежного права XI-XIX вв. М., Парад: 53-75.

5. Кром М.М. 2010. Вдовствующее царство: политический кризис в России 30-40-х годов XVI века. М., Новое литературное обозрение: 888 с.

6. Кром М.M. 2018. Рождение государства: Московская Русь XV-XVI веков. М., Новое литературное обозрение: $256 \mathrm{c}$.

7. Лисейцев Д.В., Рогожин Н.М., Эскин Ю.М. 2015. Приказы Московского государства XVI-XVII вв. М.-СПб., Центр гуманитарных дисциплин: 303 с.

8. Пенской В.В. 2019. Московский пожар 1547 г. и его политические последствия: опыт реинтерпретации. Научные ведомости Белгородского государственного университета. Серия: История. Политология, 46 (3): 479-489. DOI 10.18413/2075-4458-2019-46-3-479-489

9. Петров К.В. 2005. Значение «закона» в средневековом праве. Cahiers du monde russe, $46(1 / 2): 167-174$.

10. Петров К.В. 2008. Имел ли Судебник 1497 г. значение закона в его современном понимании? (По поводу статьи С.Н. Кистерева «Великокняжеский Судебник 1497 г. и судебная 
практика первой половины XVI в.»). В кн.: Очерки феодальной России. Вып. 12. СПб., АльянсApxeo: $365-382$.

11. Петров К.В. 2011. Принципы функционирования системы центрального управления в России конца XV-XVII вв. в европейском контексте. Ленинградский юридический журнал, 3 (25): $176-178$.

12. Пресняков А.Е. 1918. Образование Великорусского государства. Очерки по истории XIII-XV столетий. Петроград, Типография Я. Башмаков и К요 458 c.

13. Россия на путях централизации. 1982. М., Наука: 296 с.

14. Филюшкин А.И. 2009. Московская неонатальная империя: к вопросу о категориях политической практики. Вестник Санкт-Петербургского университета. Сер. 2. История. Вып. 2: 5-20.

15. Черепнин Л.В. 1960. Образование русского централизованного государства в XIV-XV веках. Очерки социально-экономической и политической истории. М., Изд-во социальноэкономической литературы: 899 с.

16. Шмидт С.О. 1973. Становление российского самодержавства. Исследование социально-политической истории времени Ивана Грозного. М., Мысль: 359 с.

17. Штаден Г. 2008. Записки о Московии. Т. 1. Публикация. М, Древлехранилище: 582 с.

18. Krom M. 2009. Les Réformes Russes du XVIe Siècle: Un Mythe Historiographique? Annales. Histoire, Sciences Sociales, 3: 561-578.

19. Barkey K. 2008. Empire of Difference. The Ottomans in Comparative Perspective. Cambridge, Cambridge University Press: 342 p.

20. Brewer J. 1989. The sinews of power. War, money and the English state, 1688-1783. London, Unwin Hyman: 253 p.

21. Carroll S. 2006. Blood and Violence in Early Modern France. Oxford, Oxford University Press: $369 \mathrm{p}$.

22. Elliott J. H. 1992. A Europe of Composite Monarchies. In: Past \& Present. Number 137. The Cultural and Political Construction of Europe: 48-71.

23. Henshall N. 1992. The Myth of Absolutism: Change \& Continuity in Early Modern European Monarchy. London \& New York, Longman: 245 p.

24. Kollmann N.S. 2012. Crime and Punishment in Early Modern Russia. Cambridge, Cambridge University Press: 504 p.

25. MacKenney R. 2002. Sixteenth Century Europe. Expansion and Conflict. London, Palgrave Macmillane: $425 \mathrm{p}$.

\section{References}

1. Alekseev Yu.G. 1991. Gosudar` vseya Rusi [Sovereign of All Russia]. Novosibirsk, Publ. Nauka: 239 p.

2. Zimin A.A. 1982. Rossiya na rubezhe XV-XVI stoletij (ocherki social'nopoliticheskoj istorii) [Russia at the turn of the XV-XVI centuries (essays on socio-political history)]. M., Publ. My`sl`: $333 \mathrm{p}$.

3. Kashtanov S.M. 1988. Finansy` srednevekovoj Rusi [Finances of medieval Russia]. M., Publ. Nauka: 248 p.

4. Kloss B.M., Nazarov V.D. 2000. Sudebnik 1497 g.: rukopis` i tekst [Judicial Code of 1497: manuscript and text]. In: Sudebnik $1497 \mathrm{~g}$. v kontekste istorii rossijskogo i zarubezhnogo prava XI-XIX vv. [Judicial Code of 1497 in the context of the history of Russian and foreign law of the XI-XIX centuries]. M.: Publ. Parad: 53-75.

5. Krom M.M. 2010. Vdovstvuyushhee czarstvo: politicheskij krizis v Rossii 30-40-x godov XVI veka [The Dowager Kingdom: The Political Crisis in Russia of the 30-40 of the 16th Century]. M., Publ. Novoe literaturnoe obozrenie: $888 \mathrm{p}$.

6. Krom M.M. 2018. Rozhdenie gosudarstva: Moskovskaya Rus` XV-XVI vekov [Birth of the state: Moscow Russia XV-XVI centuries]. M., Publ. Novoe literaturnoe obozrenie: 256 p.

7. Lisejcev D.V., Rogozhin N.M., E`skin Yu.M. 2015. Prikazy` Moskovskogo gosudarstva XVIXVII vv. [Orders of the Moscow state of the XVI-XVII centuries]. M.-SPb., Publ. Centr gumanitarny`x discipline: $303 \mathrm{p}$.

8. Penskoj V.V. 2019. The moscow fire of 1547 and its political consequences: the experience of reinterpretation Belgorod State University Scientific Bulletin. History. Political science. 46 (3): 479-489 (in Russian) DOI 10.18413/2075-4458-2019-46-3-479-489. 
9. Petrov K.V. 2005. Znachenie «zakona» v srednevekovom prave [The Meaning of the "Law" in Medieval Law]. Cahiers du monde russe, 46 (1/2): 167-174.

10. Petrov K.V. 2008. Imel li Sudebnik 1497 g. znachenie zakona v ego sovremennom ponimanii? (Po povodu stat i S.N. Kistereva «Velikoknyazheskij Sudebnik 1497 g. i sudebnaya praktika pervoj poloviny' XVI v.») [Did Sudebnik, in 1497, have the meaning of law in its modern sense? (Concerning the article by S. N. Kisterev "The Grand Duke's Judicial Code of 1497 and Judicial Practice of the First Half of the 16th Century")]. In: Ocherki feodal'noj Rossii [Essays on feudal Russia]. Release 12. SPb., Publ. Al`yans-Arxeo: 365-382.

11. Petrov K.V. 2011. Principy` funkcionirovaniya sistemy` central ’nogo upravleniya v Rossii koncza XV-XVII vv. v evropejskom kontekste [The principles of the functioning of the central management system in Russia at the end of the XV-XVII centuries. in the European context]. Leningradskij yuridicheskij zhurnal, 3 (25): 176-178.

12. Presnyakov A.E. 1918. Obrazovanie Velikorusskogo gosudarstva. Ocherki po istorii XIIIXV stoletij [The formation of the Great Russian state. Essays on the history of the XIII-XV centuries]. Petrograd, Publ. Tipografiya Ya. Bashmakov i Ko: 458 p.

13. Rossiya na putyax centralizacii [Russia on the paths of centralization]. 1982. M., Publ. Nauka: 296 p.

14. Filyushkin A.I. 2009. Moskovskaya neonatal'naya imperiya: k voprosu o kategoriyax politicheskoj praktiki [Moscow neonatal empire: on the issue of the categories of political practice]. Vestnik Sankt-Peterburgskogo universiteta. Ser. 2. Istoriya. Release 2: 5-20.

15. Cherepnin L.V. 1960. Obrazovanie russkogo centralizovannogo gosudarstva v XIV-XV vekax. Ocherki social'no-e'konomicheskoj i politicheskoj istorii [The formation of the Russian centralized state in the XIV-XV centuries. Essays on socio-economic and political history]. M., Izd-vo social 'no-e'konomicheskoj literatury` [Publishing house of socio-economic literature]: $899 \mathrm{p}$.

16. Shmidt S.O. 1973. Stanovlenie rossijskogo samoderzhavstva. Issledovanie social'nopoliticheskoj istorii vremeni Ivana Groznogo [. Formation of the Russian autocracy. A study of the sociopolitical history of the time of Ivan the Terrible]. M., Publ. My`sl`: $359 \mathrm{p}$.

17. Shtaden G. 2008. Zapiski o Moskovii [Notes on Muscovy]. Voi. 1. Publikaciya. M, Publ. Drevlexranilishhe: $582 \mathrm{p}$.

18. Krom M. 2009. Les Réformes Russes du XVIe Siècle: Un Mythe Historiographique? Annales. Histoire, Sciences Sociales, 3: 561-578.

19. Barkey K. 2008. Empire of Difference. The Ottomans in Comparative Perspective. Cambridge, Cambridge University Press: $342 \mathrm{p}$.

20. Brewer J. 1989. The sinews of power. War, money and the English state, 1688-1783. London, Unwin Hyman: 253 p.

21. Carroll S. 2006. Blood and Violence in Early Modern France. Oxford, Oxford University Press: $369 \mathrm{p}$.

22. Elliott J. H. 1992. A Europe of Composite Monarchies. In: Past \& Present. Number 137. The Cultural and Political Construction of Europe: 48-71.

23. Henshall N. 1992. The Myth of Absolutism: Change \& Continuity in Early Modern European Monarchy. London \& New York, Longman: 245 p.

24. Kollmann N.S. 2012. Crime and Punishment in Early Modern Russia. Cambridge, Cambridge University Press: $504 \mathrm{p}$.

25. MacKenney R. 2002. Sixteenth Century Europe. Expansion and Conflict. London, Palgrave Macmillane: $425 \mathrm{p}$.

\section{Ссылка для цитирования статьи For citation}

Пенской В.В., Пожарова Л.А., Туранин В.Ю. 2020. Долгий путь к «централизации»: раннемодерное Русское государство и его особенности. NOMOTHETIKA: Философия. Социология. Право. 45 (1): 103-112. DOI 10.18413/2712-746X-2020-45-1-103-112

Penskoy V.V., Pozharova L.A., Turanin V.Yu. 2020. Long way to "centralization": early modern Russian state and its features. NOMOTHETIKA: Philosophy. Sociology. Law. 45 (1): 103-112. (in Russian). DOI 10.18413/2712-746X-2020-45-1-103-112 